\title{
The fractionation of human memory ${ }^{1}$
}

A recurrent theme in the study of human memory over the last 20 years has been the question of whether it should be regarded as a unitary system, or as a collection of two or more subsystems. After a few years of relative quiescence, this topic has begun to move back into the theoretical limelight and, as has often been the case in this area, the stimulus for theoretical development has come from the study of clinical evidence from patients with memory deficits. Before going on to discuss these recent developments, it would perhaps be helpful to outline the earlier background to the controversy. (A more detailed discussion is given in Baddeley, 1983a, chapters 9-11.)

Up to and including the 1950 s, the study of memory was largely concerned with the learning of lists of words or paragraphs of prose and their retention over periods ranging from a few minutes to a few years. Memory was, implicitly at least, regarded as a single unitary system. During the latter half of the 1950s, however, a number of investigators began to observe that even small amounts of material would show signs of being forgotten over a matter of seconds, provided that the subject was prevented from continually rehearsing it, and they postulated a separate short-term memory system to account for their results (e.g. Broadbent, 1958). The 1960s saw the development of a controversy as to whether it was, in fact, necessary to assume separate systems to account for these new results, or whether existing theories could explain both sets of data (Melton, 1963). This produced a great deal of experimental work attempting to look for clear empirical evidence for or against two separate memory systems. Many apparent differences were observed, with the following three being among the more theoretically cogent.

\section{EVIDENCE FOR A DICHOTOMY}

A number of investigators noted that many memory tasks appear to behave as though they comprise two quite separate components, one relatively durable and the other quite labile. The most commonly quoted instance of this is the task known as free recall in which subjects are presented with a list of unrelated items - for example, twenty words, one at a time - and then asked to recall as many of the items as they can in any order they wish. Typically, subjects recall the last few items extremely well, and earlier items considerably less well. The tendency for the last few items to be well remembered, the so-called recency effect, disappears, however, if recall is delayed for a few seconds during which the subjects are distracted by requiring them to count or do a simple sum. In contrast, the effect of this delay on earlier items is negligible. A simple interpretation of this result is to suggest that the most recent items are being held in a brief temporary 'short-term memory' store, and are forgotten during the delay (Glanzer, 1972). ${ }^{2}$

A second apparent difference between this brief temporary storage system and the longer-term system emerges when the role of encoding in memory is studied. If subjects are required to hear and immediately recall a string of unrelated letters or words, they appear to rely heavily on the spoken characteristics of the material. Hence items that are phonologically similar to each other, such as the consonant string $B V T C P D$ or the word sequence man cad mat map can, are much less likely to be recalled accurately than otherwise equivalent but dissimilar sequences, such as $K W Y Q R L$

\footnotetext{
1 Address for correspondence: Dr Alan Baddeley, MRC Applied Psychology Unit, 15 Chaucer Road, Cambridge CB2 2EF.

- Psychologists have typically used the expression short-lerm memory to refer to retention of material over a matter of seconds, and long-term memory to refer to anything more durable. This can create confusion, since the expression short-term memory is also used by the general public, though very much more loosely. For this and other reasons, some theorists have adopted the alternative term primary memory. As will be seen, this in turn is now tending to be replaced by the more elaborated concept of working memory.
} 
or pit day pen cow bar (Conrad \& Hull, 1964; Baddeley, 1966). In the case of recalling meaningful material such as prose, this tendency shows up in the subject's ability to remember the exact wording of a sentence only if tested immediately, whereas retention of the meaning or gist of the passage is much more durable (Sachs, 1967).

A third source of evidence came from the study of neuropsychological patients. Densely amnesic patients, such as those suffering from Korsakoff's syndrome or from bilateral damage to the temporal lobes and hippocampus, while showing very impaired long-term learning ability, nonetheless have a normal ability to perform a range of tasks assumed to rely on the more temporary short-term or primary memory system. Such amnesic patients have a normal digit span and an unimpaired recency effect in free recall, despite showing very poor performance on earlier items in the free recall list (Baddeley \& Warrington, 1970). Conversely, other patients with a very specific left hemisphere lesion demonstrated normal long-term memory together with grossly impaired short-term or primary memory; when required to repeat back a spoken telephone number, the maximum length reported correctly may be as short as two digits. Such patients show impaired recency in free recall, but intact long-term memory (Shallice \& Warrington, 1970).

\section{THE MODAL MODEL AND ITS DIFFICULTIES}

By the late 1960s, these and other sources of evidence appeared to be pointing to a clear dichotomy between a temporary storage system, the short-term or primary memory store, and a more durable long-term memory system. The development of detailed theoretical models was very much in vogue at the time, and a great many variants on dichotomous models were produced, the most influential probably being that of Atkinson \& Shiffrin (1968), which being the most characteristic was often termed the modal model. This model assumed that information was fed from a series of sensory buffer stores into a limited capacity short-term store which maintained information, and in due course fed it into long-term memory. Since the rate of transfer of information to long-term memory was limited, the longer the material was held in the short-term storage system, the greater was the probability of its being transferred or copied into long-term memory. However, despite its apparent success in accounting for a wide range of data, the dichotomous view of memory began to lose popularity in the 1970s. There was no single result that disproved the dichotomous approach, but the following factors were certainly influential in reducing its popularity.

First, evidence began to accumulate that the apparently straightforward short-term component such as the recency effect in free recall could not be simply identified with the output of a short-term store. For one thing, recency effects were found that extended over minutes, hours and even weeks (Baddeley \& Hitch, 1977). Secondly, the relationship between coding and memory proved to be more complex than it first appeared, with evidence for phonological coding operative in long- as well as short-term memory. Indeed, long-term phonological memory must exist if we are to learn to talk, or to pronounce words in a new language. Finally, the neuropsychological evidence proved not to fit at all neatly into the Atkinson \& Shiffrin model. This assumes that, for long-term learning to occur, information must pass through the limited capacity short-term store. If this is the case, then patients with grossly impaired short-term retention should also have long-term learning difficulties and, as Shallice \& Warrington (1970) showed, this is certainly not the case. Such patients are indeed remarkably unimpaired in their general cognitive performance.

\section{LEVELS OF PROCESSING}

One result of the growing disenchantment with a dichotomous model was the development by Craik \& Lockhart (1972) of an alternative framework for studying human memory, that of levels of processing. This approach attempts to explain the varied phenomena associated with the long-and short-term dichotomy in terms of one basic feature, the association between the encoding of material and its subsequent memorability. More specifically, this approach suggests that, the more deeply the material is encoded, the more durable will be the memory trace. In a typical levels of 
processing study, subjects might be presented with a list of unrelated words and required to process them either vary shallowly - for example, deciding whether the word was written in upper or lower case script - or slightly more deeply - for example, by judging whether the word (e.g. DOG) rhymes with a specified comparison word (e.g. $\log$ )-or yet more deeply - for example, deciding whether a word (e.g. LION) fits into a particular semantic category (e.g. animals). There is considerable evidence to suggest that the deeper the coding, the better the subsequent learning.

The concept of levels of processing appeared to offer a welcome simplification in the field, and has generated a good deal of research. There is no doubt that it provides a good rule of thumb, and it does furthermore appear to have thrown some light on, for example, the problem of why learning is rather poorer in the elderly. Craik \& Simon (1979) showed that elderly subjects tend to encode new material less deeply and less elaborately than the young; if elderly subjects can be induced to process material as richly and deeply as young subjects, then much of the difference between the two disappears. Attempts to apply the levels of processing concept to other areas such as that of amnesia have, however, been rather less successful and, while it provides a useful general concept, there is doubt as to whether it is proving theoretically very fruitful (Baddeley, 1978, 1982a).

\section{WORKING MEMORY}

The levels of processing concept is essentially concerned with the role of coding in long-term memory; the original formulation by Craik \& Lockhart did indeed include a primary or short-term memory system, but said virtually nothing about it. The opposite is true of an approach developed by Baddeley \& Hitch (1974) which was primarily concerned with the short-term component of memory. It replaced the earlier concept of a unitary short-term store with the concept of working memory, an alliance of subsystems linked by a limited capacity central processor termed the central executive. Two subsidiary slave systems were explored in some detail: the articulatory loop which was assumed to be responsible for the phonological characteristics of much short-term storage; and the visuospatial sketch pad that created and maintained visual images. Although the concept of working memory emphasizes the storage capacity of its subsystems, their mnemonic capability is assumed to be part of their general role in other tasks. Hence the articulatory loop is part of the system for comprehending and producing speech, while the visuospatial sketch pad is part of the system for maintaining orientation in space.

So far, the concept of working memory has proved useful not only in coping with some of the anomalies encountered with the old concept of short-term memory, but has also provided a useful tool for studying other problems, ranging from the developing of short-term memory in children to its breakdown in the neuropsychological cases, and from the analysis of development dyslexia to the study of fluent reading in adults (for a review, see Baddeley, 1983 $b$; Hitch, 1984).

\section{HOW MANY KINDS OF LONG-TERM MEMORY?}

While the particular detailed formulation of working memory just described is by no means universally accepted, there is a growing consensus that the earlier concept of a unitary short-term store is oversimplified and that it is best replaced by a more complex set of interacting subsystems (e.g. Crowder, 1982). Rather more controversial is the issue of whether long-term memory in turn comprises two or more subsystems.

In 1972, Tulving suggested a distinction between two aspects of long-term memory, semantic and episodic. Semantic memory is essentially stored knowledge of the world-for example, Paris is the capital of France; the German word Hund means dog; there are 12 inches in a foot. One can contrast this with episodic memory, which involves memory for specific personal experiences such as an incident on your last summer holiday or recalling what you had for breakfast. It was suggested by Tulving that these two types of information might be stored in different systems, and some evidence in support of this appeared to be provided by the observation that amnesic patients with disastrously impaired ability to remember such episodes as what they had for breakfast, might nevertheless have 
an intact ability to perform such tests of semantic memory as are required for a vocabulary test or the verification of statements about the world (Kinsbourne \& Wood, 1975; Baddeley, 1982 $b$ ).

We have recently explored this area in some detail, using two patients who have dense global amnesia but who are otherwise intellectually unimpaired (Baddeley \& Wilson, 1983). One patient was amnesic following meningitis, the other as a result of a bilateral stroke. We observed that our patients were indeed able to perform conventional tests of semantic memory entirely adequately; their vocabulary was excellent and their ability to verify statements about the world was normal in both speed and accuracy. However, interpretation of these results is equivocal since seritantic memory tests typically probe learning that has occurred many years before the onset of amnesia, whereas episodic memory tests typically investigate new learning. Our results could therefore indicate either intact semantic and defective episodic memory, or else the preservation of learning that has occurred long ago together with impaired new learning.

One way of testing this is to look at the acquisition of new information into semantic memory. If semantic memory is entirely unimpaired, then subjects should be able to acquire new knowledge, although they may well not remember where the knowledge has come from. Observation of amnesic patients suggests that, although certain types of learning may be unimpaired, this does not apply to acquistion of new general knowledge. Amnesic patients typically do not, for example, know who is the current Prime Minister, and typically have no idea of the state of current events. They often have great difficulty learning their way around or learning the names of people such as therapists who may be treating them every day (Wilson, 1982).

A particularly striking example of the failure to register new information in semantic memory comes from a recent study by Cermak \& O'Connor (1983) in which they describe a patient who is densely amnesic, although intellectually otherwise unimpaired, following encephalitis. The patient was previously an expert on laser technology, but had ceased to work a number of years before, as a result of his illness. They showed their patient an article from a newspaper describing current developments in laser technology. He was able to understand the article and, indeed, could explain why the new developments were important. On completing the article he was asked what it was about, and was completely unable to recall; furthermore, when given specific questions about the article he was quite unable to answer them. It appears then that the registration of new information in semantic memory is not intact in amnesic patients. This may, of course, mean that semantic memory is a separate storage system, but one which relies on episodic memory for its updating.

On this interpretation one might argue that amnesic patients will be impaired in registering new information in semantic memory, but unimpaired in retrieving old information. However, this might also be true of the type of information usually assumed to be stored in episodic memory. Hence, if one wishes to argue that amnesia represents evidence for a semantic-episodic distinction, it is necessary to demonstrate that amnesic patients can retrieve old items from semantic memory, but not from episodic memory.

Cermak \& O'Connor questioned their patient about his earlier life and concluded that his recall was indeed impaired, being limited to striking features which could perhaps best be regarded as a personal semantic memory system: oft-told tales that have consolidated into knowledge about oneself rather than specific personal memories. Unfortunately, the authors do not include any equivalent data from normal subjects; such data are not readily available, but it appears to be the case that even normal subjects, when recalling incidents from many years ago, tend to behave rather like this patient, producing a few rather striking personal events, with relatively little personally experienced detail (D. Bekerian, personal communication).

We ourselves have probed the autobiographical memory of one of our two patients, and find that he does appear to be able to recall such details as the colour of the flowers carried by the bridesmaids at his wedding, or the weather at a time that a particularly striking incident happened during the war. He also reports non-striking events, such as feeling lonely while on guard, and the general tenor of his autobiographical recall does not seem to be substantially different from that of a normal subject recalling events from the distant past (Baddeley \& Wilson, 1983). Research on autobiographical memory, although developing, is still very sketchy, but our own data suggest that the memory 
performance of amnesic patients does not provide strong evidence in favour of the assumption that semantic and episodic memory involve separate systems. While there is no doubt that the semantic-episodic distinction is conceptually useful, we know of no cogent evidence against the assumption that it reflects different aspects of a single long-term memory system.

\section{WHAT CAN AMNESIC PATIENTS LEARN?}

Although the evidence for the sparing of semantic memory in amnesic patients is weak, there is very good evidence that certain types of learning may be unimpaired. The term procedural learning is often used to describe such learning, which is reflected in a change in the patient's behaviour that may be unaccompanied by any ability to recall the event that led to that change. The classic observation here is that of Claparède (1911) who on one occasion on his morning round secreted a pin in his hand before shaking hands with a patient with Korsakoff's syndrome. On the following day the patient was unable to recall the incident, but was very reluctant to shake hands.

The question of what learning is possible for amnesic patients has stimulated a good deal of research in recent years, and evidence has emerged to show that amnesic patients may be able to learn, not only conditioned responses but also motor skills, such as would be involved in a pianist learning to play a new tune on the piano or learning to type; perceptual skills, such as reading inverted writing; or more complex skills, such as solving jigsaw puzzles, and even performing quite difficult problem-solving tasks (for a review of much of this work, see Baddeley, 1982 $b$ ).

It is generally agreed that what these tasks have in common is that they allow the patient to demonstrate learning by performing the task more efficiently, while not requiring him to recollect where or when the information was acquired. Indeed, characteristically the subject will fail to remember having performed the task before, despite showing virtually normal learning. The evidence therefore seems to suggest that the system involved in this 'unconscious' behavioural learning is intact, despite the fact that the subject's recollection or awareness of experiencing the information may be grossly impaired. An exactly parallel deficit has been demonstrated in experiments using monkeys by Mishkin (1982), who has presented cogent evidence for the neurological separation of the two learning systems.

The evidence for two learning systems, one independent of conscious awareness, is reminiscent of recent developments in vision, where there is growing evidence for two separate visual systems, one associated with conscious perception, while the other is capable of providing information but is not accessible to awareness. As Weiskrantz (1978) has pointed out, there is an appealing similarity between the amnesic patient who can learn but is unaware of learning, and the 'blindsight' patient who, as a result of cortical damage, is incapable of 'seeing' objects in part of visual field, but nevertheless when pressed is able to act appropriately.

In conclusion, our view of human memory has developed very substantially over the last 25 years, moving from a simple unitary concept through a dichotomy to a position where the dichotomy itself has begun to fragment.

Current evidence suggests that the concept of a unitary short-term or primary memory system should be replaced by a concept such as working memory in which a central processor controls a number of slave systems, each specialized for the temporary storage of a particular type of information. In the case of long-term memory, the distinction between semantic and episodic memory is useful, but does not force one to assume separate underlying systems. On the other hand, the evidence for intact procedural learning in amnesic patients argues for two anatomically separate learning systems. 


\section{REFERENCES}

Atkinson, R. C. \& Shiffrin, R. M. (1968). Human memory: a proposed system and its control processes. In The Psychology of Learning and Motivation: Advances in Research and Theory, Vol, 2 (ed. K. W. Spence and J. T. Spence), pp. 89-195. Academic Press: New York.

Baddeley, A. D. (1966). Short-term memory for word sequences as a function of acoustic, semantic and formal similarity. Quarterly Journal of Experimental Psychology 18, 362-365.

Baddeley, A. D. (1978). The trouble with levels: A re-examination of Craik and Lockhart's framework for memory research. Psychological Review 85, 139-152.

Baddeley, A. D. (1982a). Domains of recollection. Psychological Review 89, 708-729.

Baddeley, A. D. (1982b). Amnesia: a minimal model and an interpretation. In Human Memory and Amnesia (ed. L. S. Cermak), pp. 305-336. Erlbaum: Hillsdale, NJ.

Baddeley, A. D. (1983a). Your Memory: A User's Guide. Penguin: Harmondsworth.

Baddeley, A. D. (1983b). Working memory. Philosophical Transactions of the Royal Society London B 302, 311-324.

Baddeley, A. D. \& Hitch, G. J. (1974). Working memory. In Recent Advances in Learning and Motivation, Vol. 8 (ed. G. Bower), pp. 47-90. Academic Press: New York.

Baddeley, A. D. \& Hitch, G. J. (1977). Recency re-examined. In Attention and Performance, Vol. 6 (ed. S. Dornic), pp. 647-667. Erlbaum: Hillsdale, NJ.

Baddeley, A. D. \& Warrington, E. K. (1970). Amnesia and the distinction between long- and short-term memory. Journal of Verbal Learning and Verbal Behavior 9, 176-189.

Baddeley, A. D. \& Wilson, B. (1983). Differences among amnesias and between amnesics: The role of single case methodology in theoretical analysis and practical treatment. Paper presented at the Conference on Human Amnesia, Princeton, New Jersey, April 1983.

Broadbent, D. E. (1958). Perception and Communication. Pergamon Press: Oxford.

Cermak, L. S. \& O'Connor, N. (1983). The anterograde and retrograde retrieval ability of a patient with amnesia due to encephalitis. Neuropsychologia 21, 213-234.
Claparède, E. (1911). Recognition et noiite. Archives Psychologiques (Geneva) 11, 79-90.

Conrad, R. \& Hull, A. J. (1964). Information, acoustic confusion and memory span. British Journal of Psychology 55, 429-432.

Craik, F. I. M. \& Lockhart, R. S. (1972). Levels of processing: A framework for memory research. Journal of Verbal Learning and Verbal Behavior 11, 671-684.

Craik, F. I. M. \& Simon, E. (1979). Age differences in memory: the role of attention and depth of processing. In New Directions in Memory and Ageing: Proceedings of the George Talland Memorial Conference (ed. L. W. Poon, J. L. Fozard, L. S. Cermak, D. Arenberg and L. Thompson), pp. 95-112. Erlbaum: Hillsdale, NJ.

Crowder, R. G. (1982). The demise of short-term memory. Acta Psychologica 50, 291-323.

Glanzer, M. (1972). Storage mechanisms in recall. In The Psychology of Learning and Motivation: Advances in Research and Theory, Vol. 5 (ed. G. H. Bower), pp. 129-193. Academic Press: New York.

Hitch, G. J. (1984). Working memory. Psychological Medicine 14, $265-271$.

Kinsbourne, M. \& Wood, F. (1975). Short-term memory processes in the amnesic syndrome. In Short-term Memory (ed. D. Deutsch and J. A. Deutsch), pp. 258-293. Academic Press: New York.

Melton, A.W. (1963). Implications of short-term memory for a general theory of memory. Journal of Verbal Learning and Verbal Behavior 2, 1-21.

Mishkin, M. (1982). A memory system in the monkey. Philosophical Transactions of the Royal Society London B 98, 85-96.

Sachs, J. S. (1967). Recognition memory for syntactic and semantic aspects of connected discourse. Perception and Psychophysics 2 , 437-442.

Shallice, T. \& Warrington, E. K. (1970). Independent functioning of verbal memory stores: a neuropsychological study. Quarterly Journal of Experimental Psychology 22, 261-273.

Tulving, E. (1972). Episodic and semantic memory. In Organization of Memory (ed. E. Tulving and W. Donaldson), pp. 381-403. Academic Press: New York.

Weiskrantz, L. (1978). A comparison of hippocampal pathology in man and other animals. In Functions of the Septo-Hippocampal System. Ciba Symposium 58,pp. 373-406. Elsevier/North-Holland: Amsterdam.

Wilson, B. (1982). Success and failure in retraining following a cerebral vascular accident. Cortex 18, 581-594. 